\title{
Finessing incivility: The professional socialisation experiences of student nurses' first clinical placement, a grounded theory
}

\author{
Juliet Thomas $^{\mathrm{a}, *}$, Annette Jinks ${ }^{\mathrm{b}}$, Barbara Jack ${ }^{\mathrm{b}}$ \\ a Faculty of Health and Social Care, Edge Hill University, UK \\ ${ }^{\mathrm{b}}$ Evidence Based Practice Research Centre, Edge Hill University, UK
}

\section{A R T I C L E I N F O}

\section{Article history:}

Accepted 26 August 2015

Available online $\mathrm{xxxx}$

\section{Keywords:}

Incivility

Student nurse socialisation

Clinical placement

Grounded theory

\begin{abstract}
S U M M A R Y
Background: Clinical practice is where student nurses are socialised into a professional role and acquire the distinct behaviour, attitudes and values of the nursing profession. Getting it right at the outset can maximise the development of a professional identity and the transmission of robust value systems.

Objectives: To explore the impact of the first clinical placement on the professional socialisation of adult undergraduate student nurses in the United Kingdom.

Design: Data of a longitudinal qualitative nature were collected and analysed using grounded theory.

Settings: First year student nurses in hospital ward placements comprising a rural District General Hospital and a large inner city Hospital kept daily unstructured diaries for six weeks.

Participants: A total of 26 undergraduate adult student nurses were purposefully sampled between 2008 and 2010 before undertaking their initial clinical placement.

Methods: Data collection and analysis used grounded theory and the key question asked of the diarists 'tell me what it is like to be a first year nurse on a first placement' was theoretically adjusted during constant comparison and as the theory emerged. Ethical approval and consent was obtained.

Results: The theory of finessing incivility comprises a conceptual framework depicting how student nurses deal with professional incivility during their initial clinical placement and sustain a student identity. Being disillusioned with their role as worker rather than learner yields a sense of 'status dislocation'. Despite needing professional benevolence, they remain altruistic and seek recompense from significant others to negotiate for learning opportunities and relocate their student status.

Conclusions: Despite the stressful transition into clinical practice rather than 'fit in', the student nurses want to belong as learners. His or her own resilience to learn nursing and be a professional student maintains their resolve, their altruism and strengthens their existing values to be benevolent towards an indifferent profession. This behaviour ultimately mirrors the social nature of the practice community.
\end{abstract}

(c) 2015 Elsevier Ltd. All rights reserved.

\section{Introduction}

Student nurse education in the UK is normally a three-year undergraduate course where students can take professional qualifications in adult, child, mental health or learning disability nursing. Students spend half their time in a university and half in clinical practice. Programmes vary but normally students undertake their initial clinical placement in the first few months of their course. Standards for pre-registration nursing education include a competency framework of achievement required of UK student nurses in order that they can register with the Nursing and Midwifery Council (NMC, 2010). These standards include; professional values, communication and interpersonal skills, nursing practice and decision making and leadership,

* Corresponding author at: Edge Hill University, Faculty of Health and Social Care (room 217), St Helens Road, Lancashire L39 4Q UK. Tel.: + 441695657033.

E-mail address: thomasja@edgehill.ac.uk (J. Thomas). management and team working. Achieving these standards is by a process of professional socialisation and therefore, successfully socialising 'neophytes' into the profession and imbuing them with professional realism of the nurse's role is the supreme aim of professional nursing programmes.

However, previous phrases used by student nurses such as 'not rocking the boat' and 'just another pair of hands' (Clouder, 2003:217, Bradbury-Jones et al., 2011:370) continue to resonate and similar anecdotal comments made by student nurse to me, were the impetus for this doctoral study the aim of which, was to gain further understanding of the early clinical experiences of student nurses and redress the paucity of research in this area (Thomas, 2013).

\section{Background/Literature}

The term socialisation has a history of varied use and various definitions of the term exist. Dimitriadou et al. (2013) suggest that the 
term generally refers to the processes by which people selectively acquire their personal values and attitudes, identify interests and develop skills and knowledge base.

Professional socialisation is a component of adult socialisation and a process by which individuals acquire the distinct behaviour, attitudes and values of a particular profession (Brennan and McSherry, 2007). An early study in the UK (Melia, 1984) focused on British student nurses construction of occupational socialisation. Melia's seminal work developed a 'compartmentalisation' model of the theory/practice divide. This discrepancy was believed to lead to a theory: practice divide in traditional pre-registration nurse education programmes in the UK. Melia (1987) also found that student nurses worked to 'fit in' and became 'two faced' as they actually did not see their training from either a service or educational perspective, just a series of hurdles to overcome in order to pass exams and achieve satisfactory ward reports from the ward sister.

In the intervening decades since Melia's original study there have been a number of pre-registration curriculum revisions in the UK aimed at lessening this theory: practice divide. (See for example, the accounts of Wilson and Startup (1991), Elkan and Robinson (1993), Gray and Smith's (1999) for project reforms (the change in programme where the training moved from hospitals to being taught in Universities) and Andrew et al. (2009), Melling (2011), and Leducq et al. (2012) for post curricular reforms). Nevertheless, some authors continue to report that student' experiences of the ideals of clinical practice still fall short of the academic content of student's programmes (Astin et al., 2005).

One of the key elements of socialisation is the transmission of a cultural value system. The transmission of nursing values was the focus of the formative work of Kramer (1974) in America who asserted that despite student nurses completing their education with raised professional values, they often lowered when beginning professional practice. Other seminal work was executed by Fretwell (1982) in the UK. The impetus for her study was one of personal tragedy and an awareness of patient helplessness. The importance of 'the little things' that Fretwell refers to as 'basic nursing' and what constitutes 'good nursing care' was a key finding.

Professional values of English undergraduate nursing students were also investigated in order to describe what it was they internalised (Kelly, 1991). Her findings revealed two perceived concepts as central to the undergraduate's professional values; these were 'respect for patients' and their autonomy and 'caring about the little things' including physical aspects of care such as care of dentures. Whilst they expected these values to be in conflict with common hospital practice, they also valued 'fitting in' and 'going along' whilst retaining their personal ideas and values until such a time that they could be implemented. However, some felt powerless to instigate these changes when newly qualified, as they believed the power remained within the hospital system and the nurse in charge (Kelly, 1991).

\section{Summary}

Despite a general benefit to the nursing profession of educational reform it is noted that many newly qualified nursing staff continue to be confined and restrained in their daily practice with negative aspects of professional socialisation including reduced morale, dissatisfaction and stress and worryingly, a reduction in the quality of patient care remaining (Mooney, 2007). Clearly, professional socialisation remains fundamental to the practice of nursing and therefore, if negative consequences occur during its process at the beginning of a student nurses journey, they may well impinge on their ability to nurse and to ultimately provide care. Understanding the processes involved will be of interest to readers in ensuring that student nurses are prepared to function in current and complex health and social environments, to contribute to the workforce and to avoid inappropriate socialisation and attrition.

\section{Methodology}

Design

The classic grounded theory perspective of Glaser (1978) was adopted for this study. Glaser' stance maintains a close affiliation with the original approach (Hall et al., 2013) where emphasis on objectivity between the researcher and the study foci reflects a need to trust in the emergence of findings from the data. Key to this approach is that the researcher does not formulate any hypothesis in advance but tries to approach the research area with as few preconceptions as possible (Glaser and Strauss, 1967). This is demonstrated in the broad aim of the study.

\section{Participants and Data Collection}

Those student nurses who were allocated to hospital ward areas for their first clinical placement were selected. Their first clinical placement lasted six weeks (30 days) offering exposure to a wide range of clinical experiences, nursing staff and other health care professionals, which was deemed to be an optimum environment to experience socialisation.

Unstructured, hand written, daily diaries were selected for optimal data collection and to enable freedom of response and the gaining of new and different perspectives. To obtain richness and in-depth detail, participants following the programme to become adult nurses were requested to tell the diary reader 'anything and everything' concerning their experiences of being a student nurse during their first clinical placement.

\section{Recruitment of Participants}

Under recruitment was a limitation and despite a complete return of 10 diaries from the first sample, non-compliance was evident from the last three samples. A total of 14 out of 30 failed to return their diaries although a solid combined word count from those who did gave a rich description of the student's experiences when constant comparison was made between the data.

In line with the aim of the study, grounded theory was chosen for its ability to focus on processes and the behaviour and perspectives of participants. The student nurses who were about to experience their first clinical placements were purposively sought out and sampled as they were considered to be able to provide rich meaningful and contextual data. Although the two hospital ward placements reflected diverse socio-economic areas their comparison was not the aim of the study.

All students training to become adult nurses were invited to participate in the study and attend a short presentation outlining details of the study. A further meeting for those interested in taking part took place and information sheets were given out and written consent to participate obtained by a staff member who was independent of the research team (Table 1).

Table 1

Characteristics of the diarists.

\begin{tabular}{lll}
\hline & Characteristics & Frequencies \\
\hline Gender & Male & 3 \\
& Female & 23 \\
Age & Under 21 & 6 \\
& $22-30$ years & 8 \\
& $31-40$ years & 8 \\
Previous healthcare experience & Over 41 years & 4 \\
& Yes & 20 \\
& No & 6
\end{tabular}




\section{Ethical Considerations and Approval}

A reflective and reflexive position was adopted and steered all personal ethical thinking and deliberation particularly as the recruited students belonged to the same university as the researcher. Therefore, a person independent of the research team arranged consent to participate and it was made explicit to the potential diarists that they could withdraw from the study at any time and without explanation or detriment to their education in any way. Confidentiality was maintained and at first reading of the diaries, any identifying characteristics of people and places were removed. Thereafter, a number allocated by the researcher referred to the diaries. In keeping with the University research governance guidelines data was stored securely both electronically and physically. Approval to undertake the study was gained from the faculty research ethics committee.

The main ethical dilemma that may have occurred during data analysis was that of reports of poor practice. It had been made clear to the participants at the beginning of the study that any incidents of practice identified in an initial scan of the diary content that was detrimental to patient wellbeing would be investigated. There were no reports of such incidents.

\section{Analysis}

Grounded theory methodology involves simultaneous data collection and analysis and open coding was done line-by-line resulting in multiple codes that were categorised, re-cycled and re-named. Properties of the categories were identified and at this stage, memos or 'hunches' about what I thought was 'going on' helped to conceptualise the emerging theory. Their main concern was conceptualised as 'experiencing incivility' that the students resolved by a process of finessing. Thus, 'Finessing Incivility' became the core category, which constantly recurred in the data and had the explanatory power to integrate all others categories and their properties. The theoretical code of 'Processing' was applied to the data to bring the theory together into one conceptual whole (Elliott and Jordon, 2010). As processing refers to 'getting something done' which can take time or happens over time involving stages (Glaser, 1978:74), this appeared to be the case.

\section{Rigour and Trustworthiness}

As a doctoral student, regular meetings and discussions took place with my professorial supervisory team who consisted of a director of studies and a supervisor. My interpretation of the data was discussed and they both coded an extract of diary data to ensure I wasn't inadvertently coding and developing categories that didn't 'fit' with the data. After we were all satisfied by the general tone of the coding and concept formation as a group, we agreed the relevance and fit of the main concern (core category) (Glaser, 1978).

\section{Findings}

The substantive grounded theory of finessing incivility comprises stages and properties that make up the conceptual framework charting the psychosocial processes that is, the thoughts and behaviour of student nurses within the social nature of the clinical placement as they deal with a basic social problem (incivility) with a basic social process (finessing). The stages and properties of status dislocation, status negotiation and status relocation are displayed in Table 2. Professional

Table 2

The grounded theory of 'finessing incivility': stages and properties.

\begin{tabular}{lll}
\hline Stage of dislocation & Stage of status negotiation & Stage of status relocation \\
\hline Disillusionment with role & Significant others & Being benevolent \\
Needing benevolence & Seeking recompense & Maintaining values \\
Being Altruistic & Brokering for learning & Recanting status
\end{tabular}

incivility was characterised by incidents of the student being subjected to rudeness, being treated harshly or simply ignored. The conceptual framework portrays how the students required resilience and a degree of finesse in order to maintain their student status and acquire knowledge of nursing practice. The following section explains the conceptual framework in more detail. The bracket following each excerpt denotes the diary respondent and stage of placement (for example D1/1 denotes the student diary and week of placement).

\section{Status Dislocation: Disillusionment with Role}

The majority of the student nurses studied experienced very early into their clinical placement some form of status dislocation, which was represented by disillusionment and disappointment with the reality of the clinical environment. These feeling were often generated by incidents of intentional or unintentional professional incivility for example;

I walked into my ward (for the first time).... Silence. No welcoming faces. A health care assistant (HCA) absorbed in the computer kept her back to me while I introduced myself. She laughed sarcastically when I asked if anyone had time to show me around (D13/1).

Other examples included such things as the students being ignored or treated sarcastically or both as seen in the above quote and for another student who had been occupied before handover;

'When I had finished I went out and the HCA said 'oh nice of you to join us' and was being really funny. I said 'I'm awful sorry for doing what I'm here to do (D15/3)

However, for some, realisation of their status dislocation and a perceived shift in their status from undergraduate learner to worker was compounded by episodes of 'unintentional' incivility; a major aspect of which was being ignored or dismissed and left on their own to 'get on with it' as attested by one student;

So that's me, a week with no mentor (D1/1)

Many of the reported comments made by the clinical staff appeared to demoralise and discourage the students who were striving to validate their status as a student nurse.

Today, I was scheduled to work with my mentor but I was told that she was off sick and I wasn't needed on that side of the ward. Without making any eye contact with me, I was more or less told to go and do whatever I wanted to wherever I wanted to (D1/1).

\section{Status Dislocation: Needing Benevolence and Being Altruistic}

Incivility in all forms whether it is intentional or unintentional is generally unpleasant. On occasions, qualified nursing staff and in particular mentors, experienced work overload and became stressed which then effected some students. However, when one student reflected on an unpleasant experience, it appeared to help them make sense of the person's behaviour and make allowances;

I kept thinking about how horrible and vulnerable the charge nurse made me feel. I reflected back to the previous day, and remembered overhearing her conversation on the phone with a social worker. The nurse was trying to send a patient home but was struggling to achieve this (D14/4).

For others, asking for help and guidance; is also met with uncivil remarks but responded too with an upbeat comment to 'finesse' the remark;

She just looked at me and said "sorry, that's not my side today, you'll have to ask someone else", and walked off. "How rude!" She looked 
at me like I was stupid. I 'felt stupid'! But still I learnt a lesson-never approach a nurse from the 'other side!' (D23/2).

Another student felt that some staff took advantage and she questioned whether anyone knew why she was there but makes a vow to be different as she states;

I felt invisible and let down. Towards the end of the placement things got better and I kept cheerful, telling myself I'm not going to be like them (D7/4).

Although frustrated and in need of kindness (benevolence) the desire to behave differently is evident.

\section{Status Negotiation: Significant Others}

Following on from status dislocation many of those studied sought to try and negotiate their learning needs. Negotiation was often achieved through the auspices of significant others. For example, some students arranged to spend time with other health professionals to increase their learning experiences;

I asked if I could observe the Occupational Therapist (OT). The ward manager thought this was a good idea! It was wonderful to see the patient outside of the ward environment (D11/3).

Many of the respondents also made reference to the existence of an effective support network between the students themselves;

Spent the afternoon shadowing a 2 nd year student. She was really helpful and friendly. I found it reassuring that she had experienced the same anxieties and fears (D23/3).

Additionally it appears that some students aligned themselves with those who could further their cause or more importantly someone who could guide and nurture them. For many of the students in the absence of their mentor the Health Care Assistants (HCAs) play a crucial role (Health Care Assistant, are nurses' aides, who have had some basic education);

There was a great HCA who I followed like a puppy (lost). She was superb and helpful. I also asked a few questions! (D22/3).

\section{Status Negotiation: Seeking Recompense and Brokering for Learning}

Having sought out significant others to assist in accessing learning, for supervision or for emotional protection, the participants were found to begin to 'push themselves forward' in later diary entries;

On a long day today and staffing levels are low again. I sat in the MDT meeting today which was good. One of the HCAs seemed to have a problem with me going and the other nurse on duty also did. I didn't let it get to me. I was there to learn. My mentor wanted me to go, I wanted to go, so I did! (D14/5.

It was as though they wanted compensation for the loss of their learning opportunities. With the help of their mentors, fellow students or a HCA they appeared to start to negotiate with the clinical staff in order to achieve their learning needs and to be treated as a student nurse. Brokering for knowledge acquisition appears to be part of the compensation that the students wanted in exchange for their working endeavours;

I did all the washes for the staff and the other jobs, so I can help do dressings and give out the medicines (D1/3).

This was seen to be in the form of learning nursing knowledge, skills or just being treated fairly. Undertaking task oriented care in exchange for more meaningful learning experiences was one example as seen in the previous quotation.

\section{Status Relocation: Being Benevolent}

In order to resolve the students' main concerns and to be able relocate their position from worker to student, a process of reconciliation or status relocation occurred. If their student nurses status was preserved, they appear to be able to deal with and manage the incivility to which they were exposed;

I have booked all my shifts with my mentor this week. I realised that the only way I am going to learn anything. Otherwise, I'm used as a HCA, nothing is explained to me and nobody wants to explain anything (D10/5).

This was achieved through being benevolent and maintaining values and generally being resilient in the face of adversity. It was also found that being benevolent was closely linked to the students being able to see the situation as the other person sees it. For example, to influence clinical staff in helping to achieving their learning needs, the student needed empathy to understand their viewpoint;

I made an extra effort with the nursing assistant but I now think with some people it doesn't matter how nice you are they will still make comments about you behind your back and then smile away nicely to your face. I am going to have to learn to have a thicker skin (D5/4).

\section{Status Relocation: Maintaining Values}

Another of the properties of status location was that of maintaining values. This was multi-faceted with one element being following correct practices as had been taught in the University;

No hoist or slide sheets were introduced. I told staff members that I have been told never to manually lift a patient or load by hand. They just seemed to ignore me. I pointed out I wasn't being awkward or judgmental. I was putting policy to practice and was merely thinking of the health and safety of the patient and myself (D7/1).

This often occurred in the face of cynical and disparaging attitudes that some clinical staff displayed prompting one student to demonstrate resilient traits;

The 'Mickey taking' can only go on so long and I stood up for myself, I used my initiative, I really wanted to learn and despite my mentor being indifferent and making me feel in the way and a nuisance, I said to her, pretend I'm not here and I'll just watch you (D14/5)

Furthermore, many of the participants seemed to be prepared to be assertive in order to maintain the standards and values they had been taught and to keep the welfare of the patients uppermost. Others also attempted to deal with the rudeness of some of the staff by affirming their own values and standards;

We all have bad days, some of us know how to be polite, act professionally, and treat others with respect regardless. Some people take it out on others. I would not let this reflect on my emotional status or my opinion. I held my head up high, politely greeted all the staff and joined them for the morning handover (D5/3).

\section{Status Relocation: Recanting Status}

Recanting status is the final property of the stage of status relocation and describes the activities that the students engage in and their beliefs with regards to maintaining their student status. It describes how the students reconcile themselves to the reality of practice and how it is not always possible to maintain a supernumerary status or not be counted as being part of the workforce. At this time the participants appeared to try and restore cordial relations with other members of the nursing team. As a stage it is not necessarily finite as part of this stage sees the student recanting their position as they move between being a worker and learner whilst holding on to their values and being benevolent towards others; 
The buzzer rang in the toilet and a HCA pointed her finger at me. I replied that I was going to observe a lumbar puncture. I told her that was what I was going to do and I did! The HCA had her mouth open but after the procedure, I thanked her for understanding (D17/4).

\section{Discussion}

A classic grounded theory approach is concerned with generating a theory that 'accounts for a pattern of behaviour which is relevant and problematic for those involved' (Glaser, 1978, p97). The presentation of a grounded theory, therefore takes the form of a "conceptual theory of explanation' that depicts how the participants share a basic social problem, which is resolved by similar social processes (Schreiber and MacDonald, 2010).

Similar to the present study the transitional period of status dislocation has been identified by a number of authors as an anxious and stressful time for novice student nurses and transcends cultural differences and international boundaries. For example, in an Irish study Timmins and Kaliszer (2002) explore the nature of stress as experienced by student nurses and found that the negative attitudes of other nurses articulated as incivility in the present study and the existence of an unfriendly atmosphere exacerbates the stress and anxieties experienced by student nurses early in their clinical allocations.

In a joint Australian/UK study Levett-Jones et al (2007) give a montage of student nurse stories of their clinical placement experiences. It was found student nurse alienation results from unreceptive and unwelcoming clinical environments and as a result distress and disengagement occurs which affected students' capacity and motivation for learning. Similarly in a Malawian study (Msiska et al., 2014 p39) also describe how the students studied felt like 'lost sheep' as they thought they had been abandoned 'to get on with it' during their clinical placements. In some ways this was reflective of the poorly resourced clinical settings students are allocated to in Malawi but nevertheless it is exacerbated by the negative attitudes of some clinical staff.

The next stage of conceptual model developed in the present study is status negotiation. One of the important properties of this stage is the role of significant others. Significant others in this study are identified as clinical staff or the students' own peers who in the absence of a designated mentor are sought out by students for support, guidance and protection. Parallels can be made with these findings and that of an Australian study undertaken by Grealish and Smale (2011). Grealish and Smale (2011 p53) suggest that students' access to meaningful clinical experiences depends on being 'let in'. This usually is accomplished through the auspices of the student's mentor. For example, when students are not 'let into' staff conversations and the practice culture per se, their learning options become limited. This sometimes results in the students undertaking what are referred to as repetitive low-level tasks in order to 'curry favour and be let in'.

Learning in the clinical setting for the students in the present study also involved them seeking out more senior students who were often more accommodating and supportive than the clinical staff. That student nurses need emotional support from each other is hardly surprising as many are in similar situations and developing friendships with each other helps in coping with the rigours of practice as Roberts (2009) found in a UK study. Roberts (2009) identifies what she termed as 'communities of friendship' (p367) amongst the student groups she studied. Similarly a Canadian study undertaken by Price (2008) gives the findings of meta-study and found that the interactions with others especially the students' own peers had a powerful influence of the early socialisation of student nurses.

The stage of status relocation was the final stage of the model and it was found that the students were sustained by their resolve to learn and to be a 'proper' student. For example, many of those studied, the negative attitudes they encountered made them feel 'horrible' and vulnerable and for some, interfered with their sleeping patterns. However, despite this most were able to rise above these unpleasant times and they rejected the pressures to be a 'worker' despite the incivility and unhelpful attitudes they encountered amongst the clinical staff. Similarly Mooney (2007) in an Irish study also noted that student nurses studied were able to transcend periods of insignificance in spite of feeling powerless and vulnerable in the face of routine and rituals that they were unable to influence.

Maintaining values was one of the properties of the final elements of the concept of status relocation. Features of this element were the students reporting how they tried to practice as they had been taught in the University. This was in the face of the cynical attitudes and belittling behaviour displayed by some clinical staff. This differed to that reported by some authors. For example, Kuokkanen and Leino-Kilpi (2000) in a Finnish study report that some of the student nurses they studied were seduced into accepting the poor clinical standards displayed by some clinical staff. As a result the students became de-sensitised to some aspects of the caring role of nurses. That this appeared not the case for the student nurses in the present study is reassuring as they were found to be steadfast and assertive in maintaining the clinical standards they had been taught. Many of the students in this study remarked that they were here to 'make a difference' and are an indication of their intentions, which Horton et al (2007) suggest is a term associated with nursing values.

\section{Limitations of the Study}

A number of limitations are associated with this study not least those related to the data collection methods used. Diary keeping relies on accurate and honest recall of events. Also there were no opportunities to gain alternative perspectives of the other social actors involved such as clinical staff. However, there is no reason to believe that the students studied were not honest and open in what they reported and their findings are similar to those found in the literature. Although the study was conducted in one University and can be considered a limitation of the study, it included participants over two years who had placements in two very different hospitals, a large urban hospital and a small district general hospital. Further research with a larger sample including students from other countries would be in invaluable.

Finally, a potential limitation of using classic grounded theory is the redundant data that is left behind. During data analysis and when searching for participants main concern, a 'core category' often emerges early on in the analysis stage. In order to search for more data that relates to this main concern, a de-limiting process begins and only data related the main concern is required, however rich and interesting it may appear. This is to ensure a parsimonious theory (Glaser, 1978).

\section{Conclusions}

The aim of this study was to explore the impact of the first clinical experience on the professional socialisation of adult student nurses in the UK. Integral to this aim was to understand the current processes and interactions involved in learning the content, skills, norms, values, attitudes, beliefs and culture of the nursing profession and the findings suggest that professional incivility remains in clinical practice and affected the student nurses in this study. It is little consolation that some studies that show that the trauma experienced during early clinical allocation lessens as the students get more experienced (Thomas et al., 2012). This is a regrettable dilemma for the nursing profession especially as many of these findings are mirrored in the findings of many other national and international studies. It is salutary to note the findings are not dissimilar to those of the early studies of student nurse socialisation described in the initial sections of this paper. It may be concluded that learning to be a nurse is apparently not a straightforward process and one that at times is unpleasant. However, the student nurses in this study demonstrated resilience and finesse in the face of adversity despite incivility towards novice and as such vulnerable student nurses continuing to confront the nursing profession. This 
does little to support national recruitment and retention drives or to halt unnecessary attrition from student nurse programmes that confronts many Universities.

\section{References}

Andrew, N., McGuinness, C., Reid, G., Corcoran, T., 2009. Greater than the sum of its parts: transition into the first year of undergraduate nursing. Nurse Educ. Pract. 9, 13-21.

Astin, F., Newton, J.M., McKenna, L.G., Moore-Coulson, L., 2005. Registered nurses' expectations and experiences of first year students' clinical skills and knowledge. Contemp. Nurse 18 (3), 279-291.

Bradbury-Jones, C., Irvine, S., Sambrook, F., 2011. Empowerment and being valued: a phenomenological study of nursing students' experiences of clinical practice. Nurse Educ. Today 31, 368-372.

Brennan, G., McSherry, R., 2007. Exploring the transition and professional socialisation from health care assistant. Nurse Educ. Pract. 7 (4), 206-214.

Clouder, L., 2003. Becoming professional: exploring the complexities of professional socialisation in health and social care. Learn. Health Soc. Care 2 (4), 213-222.

Dimitriadou, A., Pizirtzidou, E., Lavdaniti, M., 2013. The concept of socialization in nursing education. Int. J. Caring Sci. 6 (3), 314-318.

Elkan, R., Robinson, J., 1993. Project 2000 the gap between theory and practice. Nurse Educ. Today 13, 295-298.

Elliott, N., Jordon, J., 2010. Practical strategies to avoid the pitfalls in grounded theory research. Nurse Res. 17 (4), 29-40.

Fretwell, J.E., 1982. Ward Teaching and Learning: Sister and the Learning Environment RCN, London.

Glaser, B.G., 1978. Theoretical Sensitivity. Sociology Press, Mill Valley CA.

Glaser, B.G., Strauss, A.L., 1967. The Discovery of Grounded Theory: Strategies for Qualitative Research. Aldine Publications, Chicago.

Gray, M., Smith, L.N., 1999. The professional socialization of diploma of higher education in nursing students (Project 2000): a longitudinal qualitative study. J. Adv. Nurs. 29 (3), 639-647.

Grealish, L., Smale, L.A., 2011. Theory before practice: implicit assumptions about clinical nursing education in Australia as revealed through a shared critical reflection. Contemp. Nurse 39 (1), 51-64.

Hall, H., Griffiths, D., McKenna, L., 2013. From Darwin to constructivism: the evolution of grounded theory. Nurse Res. 20 (3), 17-21.

Horton, K., Tschudin, V., Forget, A., 2007. The value of nursing: a literature review. Nurs. Ethics 14 (6), 716-740.
Kelly, B., 1991. The professional values of English nursing undergraduates. J. Adv. Nurs. 16 867-872.

Kramer, M., 1974. Reality Shock Why Nurses Leave Nursing. CV Mosby, St Louis.

Kuokkanen, L., Leino-Kilpi, H., 2000. Power and empowerment in nursing: three theoretical approaches. J. Adv. Nurs. 31 (1), 235-241.

Leducq, M., Walsh, P., Hinsliff-Smith, K., McGarry, J., 2012. A key transition for student nurses: the first placement experience. Nurse Educ. Today 32, 779-781.

Levett-Jones, T., Lathlean, J., McMilan, M., Higgins, I., 2007. Belongingness: a montage of nursing stories of their clinical placement experiences. Contemp. Nurse 24 (2), $162-174$.

Melia, K.M., 1984. Student nurses' construction of occupational socialisation. Sociol Health Illn. 6 (2), 132-151.

Melia, K.M., 1987. Learning and Working: The Occupational Socialisation of Nurses Tavistock, London.

Melling, S., 2011. Transition: An Exploration of Student Nurse Experience in Their First Practice Placement. The University of Nottingham (Doctoral thesis).

Mooney, M., 2007. Professional socialisation: the key to survival as a newly qualified nurse. Int. J. Nurs. Pract. 13, 75-80.

Msiska, G., Smith, P., Fawcett, T., 2014. The "lifeworld" of Malawian undergraduate student nurses: the challenge of learning in resource poor clinical settings. Int J. Afr. Nurs. Sci. 1, 35-42.

Nursing and Midwifery Council, 2010. Standards for Pre-Registration Nursing Education. NMC, London.

Price, B., 2008. Strategies to help nurses cope with change in the health care setting. Nurs. Stand. 22 (48), 50-56

Roberts, D., 2009. Friendship fosters learning: the importance of friendships in clinical practice. Nurse Educ. Pract. 9 (6), 367-371.

Schreiber, R., MacDonald, M., 2010. Keeping vigil over the patient: a grounded theory of nurse anaesthesia practice. J. Adv. Nurs. 66 (3), 552-561.

Thomas, J. A. (2013) 'Finessing Incivility: How student nurses respond to issues concerning their status and learning during practice: a grounded theory' Unpublished PhD, Edge Hill University.

Thomas, J.A., Jack, B.A., Jinks, A.M., 2012. Resilience to care: a systematic review and meta-synthesis of the qualitative literature concerning the experiences of student nurses in adult hospital settings in the UK. Nurse Educ. Today 32, 657-664.

Timmins, F., Kaliszer, M., 2002. Aspects of nurse education programmes that frequently cause stress to nursing students-fact-finding sample survey. Nurse Educ. Today 22 203-211.

Wilson, A., Startup, R., 1991. Nurse socialisation: issues and problems. J. Adv. Nurs. 16 1478-1486. 